\title{
Segmentação Automática de Classes de Cobertura do Solo em Imagens de Sensoriamento Remoto utilizando o Mapa Auto-Organizável de Kohonen
}

\author{
Gabriela Cacilda Godinho dos Reis e Rodolfo Maduro Almeida \\ Instituto de Engenharia e Geociências - Universidade Federal do Oeste do Pará \\ 68035-110, Campus Tapajós, Santarém, PA \\ E-mail: gabihgodinho@gmail.com,rodolfo.almeida@ufopa.edu.br
}

\begin{abstract}
RESUMO
O sensoriamento remoto é um conjunto de técnicas que possibilita a obtenção de informações sobre alvos na superfície terrestre, através do registro da interação da radiação eletromagnética com a superfície, realizado por sensores remotos ou distantes. Este registro é caracterizado por meio de imagens, denominadas bandas espectrais, cujos níveis de cinza quantificam a energia eletromagnética emitida ou refletida pela superfície em faixas do espectro eletromagnético. Assim, um mesmo ponto na superfície pode apresentar diferentes valores de níveis de cinzas para cada banda espectral. $O$ foco de pesquisa deste trabalho é a segmentação de classes de cobertura do solo em imagens de sensoriamento remoto. A cobertura do solo é a caracterização do estado físico, químico e biológico da superfície terrestre como, por exemplo, floresta, área urbana, corpo d'água, solo exposto, etc. Dado um conjunto de bandas espectrais, o problema consiste utilizar métodos computacionais que possibilitam identificar as classes de cobertura do solo presentes nas imagens. Neste problema de segmentação, a imagem é tratada como uma matriz de $m$ linhas e $n$ colunas e as imagens da cena podem ser consideradas como uma matriz n-dimensional. Cada elemento da matriz, denominado pixel, possui um vetor de atributos, que contém os valores dos níveis de cinza das bandas espectrais. O problema consiste em buscar agrupamentos no conjunto de vetores de atributos e, no final, se obtém uma imagem onde cada pixel contém um rótulo que identifica a classe de cobertura do solo ao qual pertence. No geral, elas são categorizadas em classificação supervisionada, quando a identificação das classes é baseada em informação a priori que define as características da classe, e classificação não supervisionada quando, ou se fornece o número de classes desejadas e o método se encarrega de identifica-las, ou simplesmente o método por si só se encarrega em obter o número de classes e identificá-las. As redes neurais artificiais são exemplos de abordagens que podem ser supervisionadas e não-supervisionadas, a exemplo do mapa auto-organizável de Kohonen (em inglês Self Organizing Maps - SOM). Este trabalho envolve o uso do SOM para a identificação automática de classes de cobertura do solo em imagens de sensoriamento remoto. De uma maneira geral, as redes neurais artificiais são algoritmos matemático-computacionais que simulam certos comportamentos do cérebro humano, armazenando conhecimento experimental e torna-lo disponível para uso. O conhecimento é adquirido e armazenado durante um chamado processo de aprendizagem. O mapa auto-organizável de Kohonen é uma rede neural artificial com aprendizado competitivo e auto-organizado, idealizada para representar a organização estrutural presente no cérebro humano, mais especificamente na região do córtex, onde regiões fisicamente distintas são responsáveis pelo processamento de informações diferentes, como por exemplo, a fala, a audição e a visão. Diferentes entradas sensoriais são mapeadas para áreas correspondentes do córtex cerebral de uma forma ordenada, ou seja, relações espaciais entre os estímulos correspondem a relações espaciais entre os neurônios. Estímulos com características parecidas são mapeados em áreas próximas no cérebro. Tentando imitar esta característica do cérebro, o SOM realiza um agrupamento de um conjunto de dados em regiões, convertendo relacionamentos estatísticos não lineares entre dados de dimensão elevada em simples relacionamentos geométricos entre neurônios, dispostos em um arranjo espacial, usualmente representado por uma grade regular. Cada elemento do reticulado, denominado neurônio, possui um conjunto de vetores que o representa, denominados peso sinápticos. Após a etapa de treinamento, o SOM agrupa e sintetiza um volume de dados em um espaço de relacionamento topológico biodimensional. Este espaço de relacionamento, denominado mapa de características
\end{abstract}


é de suma importância para o conhecimento dos dados, e permite inferir as classes presentes em um volume de dados. Neste trabalho, os dados utilizados correspondem aos vetores de atributos dos pixels de uma imagem de sensoriamento remoto. A Figura 1 resume a metodologia. Na etapa 1, os vetores de atributos dos pixels são utilizados para o treinamento do SOM. Nesta etapa, os padrões de cobertura da imagem são resumidos em um conjunto reduzido de neurônios, e o SOM se encarrega de agrupar e dispor as relações espaciais dos dados no reticulado bidimensional. Na etapa 2, as classes dos dados são identificadas sobre o mapa de características. Como o conjunto de vetores dos neurônios resume os dados de entrada, as classes de cobertura do solo são identificadas sobre o mapa de características, e cada neurônio recebe um rótulo que o associa a uma classe. A matriz de distâncias fornece a medida de quão parecidos são os neurônios vizinhos. Se a distância for baixa, significa que os neurônios pertencem a um mesmo agrupamento. Valores elevados representam fronteiras entre os agrupamentos dos dados. Na etapa 2, a transformada watershed foi aplicada sobre a matriz de distâncias para a identificação dos agrupamentos. Na etapa 3, as classes identificadas no mapa de características são utilizadas para rotular os pixels, identificando as classes de padrões de cobertura do solo. Todo o procedimento é realizado de maneira automática. As classes são identificadas sobre o mapa de características, utilizando as suas propriedades e relações espaciais entre os vetores de peso.

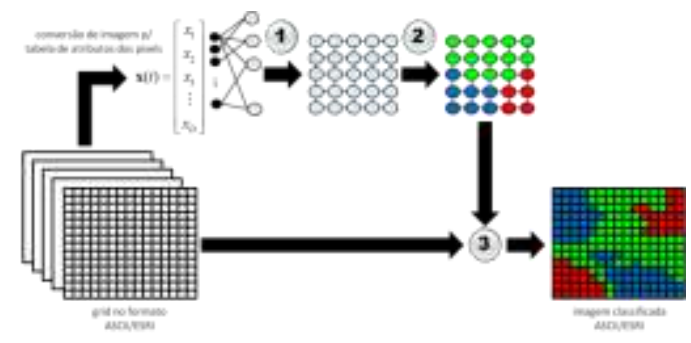

Figura 1: Resumo da metodologia.

Nos dados de entrada foram utilizadas as imagens do sensor TM (Thematic Mapper) a bordo do satélite LANDSAT 5 da região de Manaus/AM. O sensor TM opera com o registro de 7 faixas do espectro eletromagnético, sendo 3 imagens da região do visível, 3 na região do infravermelho refletido e 1 na região termal. A Figura 2 mostra os resultados da metodologia de identificação automática de padrões de cobertura.

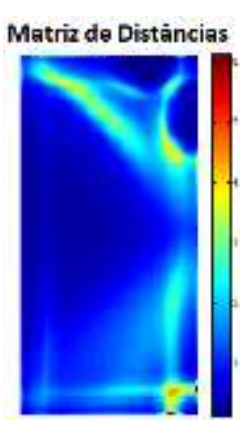

\section{Referências}

[1] H. Simon. Neural networks: a comprehensive foundation. 2. ed. New York: Prentice Hall, 2001.

[2] V. Juha.; A. Esa. Clustering of the self-organizing map. Neural Networks, IEEE Transactions on, v. 11, n. 3, p. 586-600, 2000. 